\title{
水利工程恶站电动机主保护配置探究
}

\author{
孟文福 \\ 新疆塔里木河流域巴音郭楞管理局博斯腾湖管理处 \\ DOI:10.32629/hwr.v3i9.2400
}

[摘 要] 文章从水利工程原站电动机的结构特点开始说起, 分析原站电动机存在的安全问题, 并有针对的提出合理的解决措 施, 以促进原站电动机的正常运转,确保相关工作的有序进行。

[关键词] 水利工程; 原站电动机; 解决措施

葲站是水利工程建设中非常重要的组成部分, 但在实际 运行中, 我国的水利工程泵站还存在着一系列的问题, 这些 问题的存在阻碍了水利工程作用的发挥, 故而加强对水利工 程泵站的管理, 特别是㬌站电动机主保护配置的管理研究是 尤为必要的。

\section{1 水利工程永站电动机的结构特征}

1. 1 定子结构

水利工程百站电动机分为同步电动机和异步电动机两 种类型, 不过由于两者的额定功率、转速、电压等具有相同 性, 在安装管理过程中, 为了降低其管理难度, 提升安装效率, 可以使用相同的定子结构, 且保证两种规格电动机的定子结 构可以相互转换。

以水轮发电机为例, 水利工程泵站电动机的定子结构大 多以八边形结构为主, 采用径向通风方式, 从定子铁心中间 部分开始进行通风设置, 确保散热的均匀性, 提高证电动机 的运转效率。在该定子结构中, 其内部构件采用的主要材料 及要求为:

焊接材料以中厚钢板为主; 定子线圈采用了VIP浸渍技 术; 分辨定子冲片选用了冷轧硅钢片, 定子铁心的制作则采用 叠压法。这样设置的目的为降低能源损耗, 提高导磁率。铁心 全长在 850 毫米左右, 实际使用中会将其平均分成 20 段, 每段 间的径高控制在 10 毫米。另外, 定子铁心在与机座安装时, 需要采用水轮发电机鸽尾筋结构予以固定。

\section{2 转子结构}

同步电动机的转子结构以圆盘式结构为主, 转轴材料选 用 35 号钢整锻来促进圆盘式转子结构的正常运转。同时在转 轴的中心位置实施钻孔处理, 为水泵操作油管提供必要通 道。圆盘式转子结构的优势为:

穿丝转矩较大、通风损耗量低、支架刚度强。且孔洞的 开设, 满足了电动机径向通风的要求, 加强电动机运转时的 冷却效果。同步电动机具有感应励磁磁场的作用, 在实际安 装和使用中, 会使用螺栓予以磁极固定, 并通过减小励磁电 流的方式来避免漏磁问题的产生。而在提高电动机效率上, 传统同步电动机主要以气隙极靴为主, 不过由于其不均匀特 性的影响, 现已被三段圆弧组成的极靴所代替。而异步电动 机的转子结构则以轴焊肋结构为主, 内部铁心构件采用了扇
形片叠压, 并利用斜键进行固定。而转轴结构则采用螺栓实 施加固处理。

1.3 电动机的通风冷却系统

水利工程泵站电动机运行的过程中, 电动机通风冷却系 统发挥着十分重要的作用。电机通风冷却系统由多个部件组 成, 如冷却通道、冷却器和部分增压部件, 泵站电动机通风冷 却的方式主要有三种, 一种是设置空气冷却器, 一种是径向 通风, 一种是密闭自循环通风。为了保证电机散热的效果, 系统运行中通常采用转子焊肋和通风沟旋转鼓风的方式。为 了改进其整体效果, 可在转子的两端设置小风扇, 风扇转动 的过程中, 鼓风可发挥其作用, 达到冷却的目的。电动机通风 冷却主要是转子旋转部件与风扇运动过程中产生的气流循 环流动, 气流可在定子风沟、定子机座和空气冷却器的作用 下将冷却气流输送至机座, 经定子旋转部件、风扇等部件的 增压作用, 形成闭合循环流动。

\section{2 水利工程永站电动机安全问题产生的原因}

2.1 定子过热问题

定子过热问题一般出现在同步电动机内, 而该问题产生 的原因有: 一是电动机拖动系统的负载过大。水利工程百站 同步电动机出现的拖动系统荷载过大, 主要是由于水泵在运 转中, 被水草、垃圾等其他物体缠绕, 有杂质进入到叶轮室内, 使水泵转动时摩擦阻力增大, 输出功率增加, 输入和输出不 成正比, 进而影响电动机运行的稳定性和高效性。

二是定子通风系统运转异常。水利工程建设大多位置偏 远地区内, 其空气环境质量较为复杂, 很容易受到外界环境 的影响, 导致定子通风系统出现不同故障。例如, 在亚热带潮 湿气候中, 空气中的湿度较大, 灰尘很容易堆积在定子通风 系统中, 进而导致通风系统堵塞, 热量无法及时消散, 随着时 间的推移, 电动机温度不断升高, 影响其运行效率。

三是励磁电流过大。励磁系统是同步电动机的核心系统, 当励磁电流增大时, 定子电流也会剧烈增加, 定子绕组铜耗 量增大且问题急剧升高, 导致定子出现过热的故障。

\section{2 集电环火花严重问题}

集电环花火的出现会使同步电动机无法正常启动或存 在异常停机的情况。而集电环火花产生的原因为, 同步电动 机在启动后, 因受到潮湿环境的影响, 碳粉会大量的吸附在 
电动机两集电环间的绝缘套管上, 降低绝缘套管的绝缘性 能。这时转子较高的感应电压就会对集电环上的碳粉间隔层 造成较大的击穿电压, 使得集电环出现短路情况, 破坏导电 杆或支撑件, 使其变形或损毁, 影响电动机的正常使用。当出 现集电环与电刷之间的接触压力不够、设备型号不匹配等情 况时, 集电环与电刷之间会出现火花, 从而降低电动机的运 行效率。

\section{3励磁系统故障}

在水利工程建设中, 因受到技术及经济条件等方面因素 的影响, 一些洜站的励磁装置相对较为老旧, 很难满足现今 智能化控制的需求。且这类的洜站电动机在启动过程中, 消 耗的时间较长, 且存在较多问题, 无法保证电动机的安全运 行, 再加上保护装置不完善, 经常出现跳闸、短路问题, 破坏 了电动机运行的稳定性。

\section{3 水利工程永站电动机问题的解决措施}

3.1 定子过热问题的解决措施

综上所述, 定子过热产生的原因一方面是由于杂质混入, 增加运阻力, 另一方面则是因为散热系统故障引发的问题。前 者可将混入的杂质予以有效清除, 恢复电动机的正常运转, 后者则需要实施定期的除尘作业, 避免因热量无法散发而引 发各种问题。同时, 还可通过安装通风机来增强空气流通效 果, 降低电动机的温度。

\section{2 集电环火花问题的解决措施}

首先, 做好集电环的日常检修和维护工作, 技术清除附 着在集电环上的碳粉; 其次, 对集电环的对地绝缘电阻值进 行检测, 如果发现绝缘电阻值较低, 则需检查和更换相关设 备, 促进集电环的正常运行; 再次, 合理调整集电环与电刷之 间的压力, 避免电动机出现短路等问题。同时在压力调整过 程中, 还要对集电环与电刷设备实行检查, 确保其型号的匹 配, 禁止不同规格电刷应用在同一集电环中; 最后, 用砂纸沿 集电环表面的圆弧方向进行打磨, 使其表面光滑平整, 以消 除集电环表面粗粘的情况, 促进集电环与电刷的高效运行。

\section{3 合理改造励磁系统}

在励磁系统改造升级中, 可合理应用DJL型同步电机, 提 升励磁系统的自动化、智能化控制水平, 保证电动机启动和 运行的安全性, 避免损伤的形成。且利用DJL同步电动机, 可 通过数字式精密调节器和集成电路模拟调节器对励磁系统 中的硬件设备予以优化调整, 提高系统运行质量, 加大监管
力度, 以减少电动机运行中问题的产生。

3.4开展洜站电动机的常规检查

为了改进水利工程泵站电动机的运行质量, 应做好泵站 电动机的常规检查作业, 合理设置主保护配置, 及时发现存 站电动机运行中存在的问题, 并加以控制, 降低运行危险。在 泵站电动机常规检查中, 可通过声音、气味及触感的辨识来 判断电动机是否存在故障问题。在声音识别中, 原站电动机 正常的工作声音应该是嗡嗡声, 且声调保持一致, 不会存在 变化情况, 如果在检查中发现电动机的运行声音较粗或者在 正常元转声音中伴随着嘶嘶声, 则说明电动机存在安全故 障; 在利用气味辨识中, 泵站电动机正常运转下是不会散发 出任何味道的, 一旦出现味道, 则说明电动机内一些零部件 运转存在高温或烧焦情况, 这就需要工作人员加大重视, 检 查气味产生源头, 然后制定合理控制措施。在触感辨识中, 触摸外壳能够大概判断电机的温度是否升高, 如果电机外壳 过热就需要检查负荷及电压的情况, 排除故障。

\section{5 合理设置电动机保护装置}

施工人员可将电子电动机保护器、软启动器、微机电动 机保护装置安装在洜站内, 起到保护电动机的作用。在装置 设置中, 需要对检测线电流的变化情况进行及时了解和掌握, 确保保护功能的充分发挥, 提升电动机的运转效率。另外, 可通过负序分量法和差流法对保护装置的不平衡电流实行 检测, 及时做好相应的处理措施, 避免突然跳闸等对其的影 响, 从而增大保护装置的利用率, 保证电动机的安全运行。

\section{4 结语}

为了改进水利工程建设效果, 促进其功能的成分发挥, 加强对泵站电动机主保护配置的探究是尤为必要的。企业需 针对泵站电动机存在的问题, 制定科学合理的解决措施, 以 提升洜站电动机的运行安全, 有效提高水利设施的运转效率, 减少危险的发生, 进而为人民的生活及国民经济的发展提供 坚实的保障。

\section{[参考文献]}

[1]陈德虎,段政,韩之刚.水利工程原站群管理与维护方 法分析[J].门窗,2017(06):195.

[2]韩继伦.机电设备在大型水利百站的安装和检修 [J]. 中国设备工程,2017(19):69-70.

[3]余添兴.水利葲站机电设备安装和检修技术分析[J]. 科技视界,2019(20):80-81. 